\title{
Serum Leptin Levels and Well-Differentiated Thyroid Cancer: A True Association: Reply
}

\author{
Tarek Ezzat Abdel-Aziz ${ }^{1,2} \cdot$ Rania Abdel Rehem ${ }^{3} \cdot$ Waleed Abo Elwafa $^{1}$
}

Published online: 24 June 2015

(C) Société Internationale de Chirurgie 2015

\section{Dear Editor,}

We would like to thank Dr Sertoglu et al. for their interest and constructive comments towards our recently published article investigating the relation between welldifferentiated thyroid cancer and serum leptin levels [1], [2].

Concerning the question as to whether obesity has influenced leptin levels through inflammatory processes, we acknowledge the role of a chronic inflammatory process that is associated with obesity through mediation of cytokines [3], [4]. We have measured both erythrocyte sedimentation rate and $\mathrm{C}$-reactive protein which are a part of the routine work up for all our patients. There was no significant difference between the levels in cases and control, and therefore, this was not mentioned in the original study. There are several factors which affect serum leptin levels, and to overcome this problem, control serum leptin levels were measured to remove the effect of bias and reveal the true association between serum leptin levels and well-differentiated thyroid cancer [1].

Dr Sertoglo has also raised another important question regarding the dietary intake of the patients and their influence on the serum leptin levels with special emphasis on omega-3 fatty acid. The intake of omega-3 is not a

Tarek Ezzat Abdel-Aziz

t.abdel-aziz@ucl.ac.uk

1 Endocrine Unit, Department of General Surgery, Faculty of Medicine, Alexandria University, Alexandria, Egypt

2 General and Endocrine Surgery Unit, University College London Hospital, 235 Euston Road, London NW1 2BU, UK

3 Internal Medicine Department, Endocrinology, Faculty of Medicine, Alexandria University, Alexandria, Egypt regular supplement in our country, and therefore its effect has not been studied. Fish, however, which contains omega-3, is a major constituent of the diet of many people in Alexandria as it is a Mediterranean city. The effects of this may influence leptin levels but would be very hard to study. It is worth mentioning that we reviewed the dietary intake of all patients in the study and found no difference in dietary constituents.

We continue to study the relation between serum leptin levels and thyroid cancer and will take Dr Sertoglo's comments into account in our future studies.

Conflict of interest The authors state that there is no conflict of interests regarding the publication of this paper.

\section{References}

1. Sertoglu E (2015) Importance of factors affecting serum leptin levels. World J Surg 39:1587-1588. doi:10.1007/s00268-0142931-2

2. Rehem RA, Elwafa WA, Elwafa RA et al (2014) Study of serum leptin in well-differentiated thyroid carcinoma: correlation with patient and tumor characteristics. World J Surg 38:2621-2627. doi:10.1007/s00268-014-2634-8

3. Lang K, Ratke J (2009) Leptin and Adiponectin: new players in the field of tumor cell and leukocyte migration. Cell Commun Signal 7:27

4. Wu MH, Chou YC, Chou WY et al (2009) Circulating levels of leptin, adiposity and breast cancer risk. Br J Cancer 100:578-582 